\title{
PALABRAS EN OCASIÓN DE LA ENTREGA DEL DOCTORADO HONORIS CAUSA A ANÍBAL QUIJANO OBREGÓN
}

Texto de la conferencia pronunciada por el Dr. Sergio Villena Fiengo en el acto académico de entrega del Doctorado Honoris Causa de la Universidad de Costa Rica al Dr. Aníbal Quijano Obregón, realizado en la Sede Rodrigo Facio de esta institución, en el marco del XXX Congreso de la Asociación Latinoamericana de Sociología (ALAS), el 1 de diciembre del 2015.

El Consejo Universitario de la Universidad de Costa Rica me ha otorgado el honor de presentar a nuestra comunidad al profesor Aníbal Quijano Obregón, a quien hoy nuestra casa de estudios distingue -y de esa manera se distingue- invistiéndole con el mayor reconocimiento que otorga al mérito académico e intelectual: el Doctorado Honoris Causa.

Presentar una semblanza intelectual de Aníbal Quijano no es una tarea fácil de acometer, por la extensa, fructífera y comprometida trayectoria que él, como sociólogo, ha construido durante más de seis décadas de persistente labor. Hecha esa necesaria advertencia, permítanme, sin embargo, ensayar una semblanza del hombre y de sus circunstancias, es decir, de Aníbal Quijano y de Nuestra América, región que por él es pensada, sin duda, desde su natal Perú.

Aníbal Quijano nace en 1928 en la localidad de Yanama, provincia de Yungay. Se gradúa como Bachiller en Historia en la Facultad de Letras en la Universidad Nacional Mayor de San Marcos, una de las más antiguas casas superiores de estudios de Nuestra América, situada en la ciudad de Lima. Su primera publicación -Ensayos Escogidos de José Carlos Mariátegui, en 1956- anuncia ya una de sus principales pasiones: la interpretación y enriquecimiento de la obra del Amauta, tanto en su vertiente sociológico política, como en su veta cultural. Testimonio de su temprana preocupación por la cultura es también la edición y publicación de una Antología del cuento Latinoamericano (1957).

El profesor Quijano realizó estudios de posgrado en sociología en la Facultad Latinoamericana de Ciencias Sociales (FLACSO, Chile), institución intergubernamental 
creada con el respaldo de UNESCO en 1957 con el fin de afianzar el incipiente proceso de institucionalización y profesionalización de las ciencias sociales en la región. Recordemos que en esa institución se formaron también dos pioneros de la sociología centroamericana: Eugenio Fonseca Tortós y Edelberto Torres Rivas. Como testimonio de ese acercamiento hacia las ciencias sociales, Quijano publicará sus primeros -y únicos, hasta donde alcanza mi conocimiento- textos sobre sociólogos no latinoamericanos: Saint Simon y Wright Mills.

Quijano culmina su formación académica formal al obtener su Doctorado en 1964, en la Facultad de Letras de la Universidad Nacional Mayor de San Marcos. Su tesis tratará sobre "La Emergencia del Grupo Cholo en el Perú" (1964), temática que muestra claramente su opción por la ciencia social y lo sitúa en las problemáticas que en ese momento preocupan a la naciente "Sociología crítica Latinoamericana", que emerge después de la revolución cubana como respuesta a la sociología de la modernización y al desarrollismo, característicos de la "fase científica" de las ciencias sociales latinoamericanas.

Quijano devendrá uno de los protagonistas del debate en torno a la dependencia en América Latina, a la par de figuras como F. Weffort, E. Faletto, F. H. Cardoso, A. Gunder Frank, V. Bambirra, T. dos Santos y F. Hinkelammert, entre otros. En este periodo, considerado con justicia la edad de oro de las ciencias sociales latinoamericanas, él realizará un conjunto de aportes importantes a la discusión sobre los límites al desarrollo y el cambio social, en particular sobre la problemática de la urbanización y la marginalidad en las sociedades del capitalismo dependiente.

El sociólogo peruano aportaba al debate de la dependencia realizando "una análisis concreto de una realidad concreta", pensando el Perú en toda su complejidad. Para ello acuñó la noción de "heterogeneidad estructural", enfocada en las particularidades de los procesos socioeconómicos -en ese marco acuño la categoría "polo marginal"-, sin por eso olvidar los problemas socioculturales -es decir, al proceso de "cholificación" del Perú. El concepto de "heterogeneidad estructural" y sus manifestaciones culturales marcará pauta en el pensamiento latinoamericano, estableciendo afinidades electivas con nociones como la de "sociedad abigarrada" del boliviano René Zavaleta, así como con la de "modernidad barroca" del ecuatoriano Bolívar Echeverría.

Acorde con el enfoque relacional y mundial de la teoría de la dependencia, Quijano pensaba en su país no como una realidad aislada o autocontenida, sino que la enmarcaba en el conjunto de América Latina, región que al mismo tiempo ubicaba en el sistema económico capitalista internacional. Todo ello, manteniendo un fructífero diálogo con intelectuales de toda la región y participando en los debates de la época (algunos de ellos, en el marco de la CEPAL) e incluso elaborando trabajos en coautoría, como testimonian algunas publicaciones con el intelectual colombiano Antonio García. Es también por esa época que las contribuciones de Quijano empiezan a circular fuera de América Latina, siendo traducidas al italiano, el inglés, el francés y el alemán. 
Esta producción temprana de Quijano destaca tanto por su originalidad intelectual como por su compromiso político, compromiso que por esa época sería también un componente fundamental del ethos sociológico latinoamericano, como lo muestra la reflexión y trayectoria, entre otros, del sociólogo colombiano Orlando Fals Borda. Desde luego, el compromiso político de la sociología crítica -opuesto a la "neutralidad valorativa" pregonada por la sociología de la modernización- tenía consecuencias incluso personales, las cuales, en el caso de Quijano, significaron su expulsión de la Universidad de San Marcos, casa de estudios a la que retornará muchos años después, para posteriormente ser nombrado profesor emérito en el año 2006.

Hacia fines de los sesenta, Perú dará un giro hacia un reformismo militar y Aníbal Quijano dedicaría sus esfuerzos intelectuales a comprender las particularidades del régimen "revolucionario" de Velasco Alvarado, contemporáneo del experimento socialista por vía democrática en Chile, tema al que también dedicará algún texto. Durante esos años, reflexiona de manera sostenida sobre los alcances del reformismo militar, los peligros del imperialismo y sobre el papel de la clase obrera en ese proceso de transformación social, sin abandonar sus preocupaciones por la urbanización dependiente, la marginalidad y la cultura.

En el ocaso de los años setenta, Quijano centrará su reflexión en los fracasos de los movimientos reformistas y los problemas de las formaciones de izquierda, incorporando a su reflexión los temas de la relación entre el socialismo y la democracia. Es también el periodo en que retornará al estudio de la historia, revisando el periodo de los años treinta en su país, revisitando una vez más la obra de José Carlos Mariátegui. Fruto de esta última labor será la publicación de Introducción a Mariátegui (1982) un pequeño pero importante libro que -editado en México por Era-cumplirá una labor fundamental de acercar a los jóvenes estudiante de Ciencias Sociales a la obra imprescindible del autor de los "Siete Ensayos de Interpretación de la Realidad Peruana".

La preocupación por el legado mariateguiano ha sido una de las constantes en la obra de Quijano. Como señalamos, su primera publicación en 1956, fue una antología de textos del Amauta. En 1982, publicó su Introducción a Mariátegui y en 1987 un artículo -que recuperaría diversas reflexiones que por entonces había dedicado al pensamiento y la sociología latinoamericana- con el título "Mariátegui y la tensión del pensamiento latinoamericano" (Hueso Humero, No. 21, Lima). Cuatro años después publicó una antología titulada José Carlos Mariátegui. Textos básicos (México, F.C.E., 1991), con un extenso prólogo y comentarios introductorios a cada sección. Publicó también diversos artículos en el marco de la conmemoración del Centenario del nacimiento de Mariátegui, celebrado en 1994, así como un extenso estudio sobre los Siete ensayos de interpretación de la realidad peruana, el cual fue incluido como prólogo en una edición de ese texto por la Editorial Ayacucho (Caracas, 2007). 
Hacia fines de los años ochenta, Quijano amplía sus intereses hacia los “Nuevos temas, nuevos contenidos" que la época planteaba, principalmente hacia los problemas de la cultura y en particular hacia la cuestión de la utopía. Participa en los debates sobre posmodernidad que venía promoviendo CLACSO, así como en las reflexiones sobre el derrumbe del bloque socialista, a partir de la experiencia peruana de la década de los ochenta, marcada por la irrupción de movimientos armados como Sendero Luminoso y el MRTA. En un permanente contrapunto entre las dimensiones socioeconómica, sociocultural y sociopolítica, mostraría también creciente interés por el emergente neoliberalismo, prestando atención a los cambios en los conceptos de lo privado y lo público e indagando sobre las "nuevas formas de heterogeneidad estructural en América Latina".

En los albores de la década de los noventa, preocupado por "recuperar la utopía", Aníbal Quijano presentaría su más conocida contribución, al menos para las nuevas generaciones: la cuestión de la "colonialidad del poder". Esta categoría - parafraseo uno de sus textos- se origina y mundializa a partir de América, constituyéndose en uno de los elementos constitutivos y específicos del patrón mundial de poder capitalista. En la mirada de Quijano, este patrón se funda en la imposición de una clasificación racial/étnica de la población del mundo como piedra angular de la estructura social y la dinámica del poder que opera en cada uno de los planos, ámbitos y dimensiones, materiales y subjetivos, de la existencia cotidiana, pero también a escala macrosocial.

Esta elaboración encuentra un terreno intelectual y políticamente fértil en el marco de las polémicas en torno a los 500 años, controversia que hacer evidente a nivel internacional algo que ya tenía al menos una década de estar ocurriendo en algunos países de la región: la emergencia de un poderoso movimiento social, político, intelectual y cultural de corte indígena. Esta nueva veta, que recupera y enriquece su extendida reflexión y exploración sobre la relación entre heterogeneidad estructural, procesos socioculturales y cambio social, será continuada en esos años en colaboración con el influyente sociólogo estadounidense Immanuel Wallerstein, con quien elaborará también la categoría de "americanidad".

Cabe recordar que esos son momentos de debate intenso sobre el futuro de las ciencias sociales, pues es entonces que se discute sobre la crisis de los paradigmas y el fin de la modernidad, así como el momento en que se produce la irrupción de lo que unos lustros después vendría a denominarse "epistemologías del sur". En ese sentido, la colaboración de Quijano con Wallerstein es fundamental en la renovación del pensamiento social a nivel mundial por la cual abogaba ese sociólogo crítico norteamericano, por entonces presidente de la International Sociology Association y director de la Comisión Gulbenkian, cuyo informe "Abrir las ciencias sociales" (1996) constituye un documento fundacional en la renovación de las ciencias sociales en una perspectiva poscolonial. 
En 1995 la elaboración de la teoría de la "colonialidad del poder" debe compartir las preocupaciones de Quijano con la urgencia por pensar el Perú en el marco del fujimorismo, régimen que, envalentonado con su "éxito" militar sobre Sendero Luminoso y el MRTA, tiende cada vez más hacia el autoritarismo de corte neoliberal. En franca oposición a esa tendencia, Quijano asume una intensa actividad como intelectual público, interviniendo en los debates políticos, asumiendo una posición crítica beligerante contra el gobierno de Fujimori.

En estos años tengo el honor de conocer personalmente a Aníbal Quijano, en un seminario sobre Neopopulismo y democracia organizado en Ecuador por FLACSO y la fundación F. Ebert, lo que me permite descubrir también su extraordinaria calidez humana y sus grandes dotes de conversador. Pude hablar con él de manera informal sobre diversos temas, entre los cuales recuerdo una interesante reflexión suya sobre las razones del éxito y el declive del voleibol femenino del Perú desde una perspectiva que, tal vez, podríamos llamar hoy la "colonialidad del deporte". De esa conversación, nació también la idea que culminó en la edición de quizás la única publicación con una contribución suya en Costa Rica: el Cuaderno de Ciencias Sociales de FLACSO n. ${ }^{\circ}$ 96, con el título Neopopulismo y democracia. Estudios andinos, el cual incluye también textos de Fernando Mayorga (Bolivia) y Carlos de la Torre (Ecuador).

A inicios del nuevo milenio, Quijano se vinculará con el denominado -no sin controversias- grupo Modernidad/Colonialidad, en el cual participarán varios influyentes pensadores -entre ellos Santiago Castro-Gómez, Walter Mignolo, Ramón Grosfoguel, Nelson Maldonado, Zulma Palermo, Edgardo Lánder, Enrique Dussel, Boaventura de Sousa, etc. - que han contribuido a la reflexión sobre la problemática de la colonialidad. El aporte de Aníbal Quijano a este debate ha sido seminal, pues la categoría de "colonialidad del poder" constituye la piedra angular en torno a la cual ha girado el debate protagonizado por estos intelectuales y otros -como la socióloga boliviana Silvia Rivera Cusicanqui y la intelectual argentina Rita Segato, entre otros y otras- que, sin pertenecer a ese "grupo", han abonado a esa discusión.

A riesgo de simplificar en exceso, la tesis fundamental en este debate puede formularse en los siguientes términos: La colonialidad no es un estado de cosas que se opone a la modernidad o que la precede, sino que forma parte integral -dialécticade los mismos procesos de modernización. La colonialidad es el "lado oscuro" pero constitutivo de la modernidad y, como ella, comienza con el arribo de Colón a tierras americanas. Más aún, la colonialidad ha marcado todas las variantes de los procesos de implantación del capitalismo y la modernidad en las periferias, pero también los procesos revolucionarios que han tenido lugar en nuestra región.

Para ir concluyendo, quisiera enfatizar -utilizando categorías agustinianasque la extensa y multifacética trayectoria de Quijano, ha sido guiada por una 
extraordinaria libido conoscendi (amor por el conocimiento) inspirada no en la libido dominandi (amor por el poder) sino en la libido sentendi (amor por la vida). En ese afán, Aníbal recoge y enriquece la obra de muchos lúcidos y apasionados pensadores latinoamericanos, entre los cuales él mismo ha destacado la figura de Mariátegui, de quien es oportuno retomar una pregunta fundamental que formuló en 1925 en uno de los "Textos básicos": ¿Existe ya un pensamiento característicamente hispano-americano?

Noventa años después, la respuesta es menos pesimista que la que el mismo Amauta ofrecía: hoy -me atrevo a decir- sin duda existe un pensamiento característicamente nuestro-americano. Existe, desde luego, gracias a aquellos próceres intelectuales que -como señalara el centroamericano José Cecilio del Valle en 1825- hicieron de la "América [latina] su preocupación exclusiva y su objeto de estudio más digno", gracias a aquellos que -como señaló Simón Rodríguez-entendieron la originalidad de América Latina y prefirieron errar para crear antes que copiar torpemente las ideas de otras realidades, pero también gracias a aquellos que -como pedía Martí-entendieron que para hacer germinar el tronco latinoamericano había que injertar las naciones del mundo en él. En fin, existe un pensamiento nuestro americano gracias a aquellos que -como el propio Mariátegui- tuvieron la lucidez de pensar latinoamericana desde su propia especificidad y construir un conocimiento que no es "ni calco, ni copia", sino "creación heroica".

El gran mérito de Aníbal Quijano, por el cual hoy nuestra universidad le otorga el Doctorado Honoris Causa, es haberse apropiado y enriquecido sustantivamente ese valioso legado, en el cual hay que incluir otros pensadores que abonaron a la gran tradición intelectual peruana de la que sin duda se ha nutrido nuestro invitado, comenzando con Guamán Poma de Ayala y el Inca Garcilaso de la Vega. Esa tradición fue prolongada y enriquecida en el siglo XX por pensadores de la talla de Mariátegui y Haya de la Torre -ambos muy influyentes en Costa Rica, donde contribuyeron asiduamente al Repertorio Americano dirigido por Joaquín García Monge-, pero también por otros pensadores notables como Valcárcel y Arguedas. Más recientemente, el pensamiento crítico peruano se ha nutrido con los aportes de Alberto Flores Galindo, Heraclio Bonilla y Carlos Iván Degregori, entre muchos otros.

Pero la tarea de construir un pensamiento nuestro americano no está culminada. Lo muestra la infatigable labor de Quijano, que constantemente nos plantea el reto fundamental de repensar en colectivo la historia latinoamericana de los últimos 523 años a partir de la categoría de "colonialidad del poder". El desafío que Aníbal nos deja y que enfrentamos, como universitarios centroamericanos y latinoamericanos, es estudiar, comprender y combatir las nuevas formas que asumen la colonialidad en el marco de la globalización neoliberal, pero también los alcances y las posibilidades de remontar esa herida histórica en los gobiernos 
llamados posneoliberales. El desafío es, en fin, superar la colonialidad, poner de una vez por todas fin a esa "vieja maldición" que consiste en mirarnos con los ojos del dominador. Gracias maestro por inspirarnos a recuperar el coraje de repensar el pasado, confrontar el presente e imaginar un futuro mejor para los pueblos de Nuestra América.

Muchas gracias.

Sabanilla Montes de Oca, 1 de diciembre de $2015^{1}$

\section{Nota}

1 Este texto es una versión revisada del que fue leído en la ceremonia de entrega del Doctorado Honoris Causa al profesor Aníbal Quijano por parte de la Universidad de Costa Rica. Agradezco a Jesús Bedoya la elaboración de la bibliografía, la cual se realizó principalmente con base en la presentada en las dos antologías de la obra de Aníbal Quijano que se incluyen a final del listado de textos. Agradezco también al Dr. Jorge Rovira y al Dr. Carlos Sandoval, por la iniciativa de esta publicación en el Anuario de Estudios Centroamericanos.

\section{Libros y artículos}

(1956) (ed.) Ensayos Escogidos de José Carlos Mariátegui. Lima: Primer Festival, Patronato del libro peruano.

(1957) (ed.) Antología del Cuento Latinoamericano (Selección y notas de Aníbal Quijano). Lima: Populibros.

(1962) “C. Wright Mills, conciencia crítica de una sociedad de masas" en Revista del Museo Nacional. Tomo XXXI: 305-313.

(1964) “Imagen Saintsimoniana de la sociedad industrial” en Revista de Sociología. Universidad Nacional Mayor de San Marcos - Departamento de Sociología, Facultad de Letras. Vol. 1, N. 1: 49-85, julio-diciembre.

(1964) "La Emergencia del Grupo Cholo y sus implicaciones en la sociedad peruana" en Memorias del VII Congreso Latinoamericano de Sociología.

(1964) "La poesía: una praxis" en Haraui. Año 1, N. 2 2, enero.

(1965) "Imagen y tareas del sociólogo en la sociedad peruana” en Letras. Revista de la Facultad de Letras. Lima: UNMSM.

(1965) "El movimiento campesino peruano y sus líderes" en América Latina. Instituto Latinoamericano de Pesquisas Sociais. Año VII, N. 4.

(1965) La emergencia del grupo cholo y sus implicaciones en la sociedad peruana. (Tesis doctoral). Universidad Nacional Mayor de San Marcos, Facultad de Letras. Lima.

(1966) “Los movimientos campesinos contemporáneos de América Latina” en Lipset, S. M. y Solari, Aldo (eds.). Las Elites Contemporáneas de América Latina. Buenos Aires: Paidós.

(1966) "Notas sobre el concepto de 'marginalidad social" en CEPAL - División de Asuntos Sociales. Santiago de Chile.

(1966) [seud.] Condoruna, José “Las experiencias de la última etapa de las luchas revolucionarias en el Perú" en Estrategia N. ${ }^{\circ}$ 3. Santiago de Chile. 
(1966) “El proceso de urbanización en América Latina” en CEPAL - División de Asuntos Sociales. Santiago de Chile.

(1967) "La urbanización de la sociedad en América Latina" en CEPAL - División de Asuntos Sociales. Santiago de Chile.

(1967) “Naturaleza, situación y tendencias de la sociedad peruana contemporánea (un ensayo de interpretación)" Centro de Estudios Socio-Económicos, Universidad de Chile. Santiago de Chile

(1967) “Urbanización y tendencias de cambio en la sociedad rural en Latinoamérica" CEPAL - División de Asuntos Sociales.

(1967) “Diagnóstico de la situación de los recursos humanos". Servicio del Empleo y de Recursos Humanos. Ministerio de Trabajo. Lima.

(1968) "Dependencia, cambio social y urbanización en Latinoamérica" en Revista Mexicana de Sociología. UNAM - Instituto de Investigaciones Sociales. Año 30, Vol. XXX, N. ${ }^{\circ}$ : 525570, julio-septiembre.

(1968) [seudónimo] Collar, Ramón “El golpe militar en el Perú, en el contexto de la realidad peruana y latinoamericana" en Cuaderno de Ciencias Sociales. Centro de Estudiantes de Ciencias Sociales de la Universidad Agraria y Centro de Estudiantes de Historia Universidad Nacional Mayor de San Marco. Lima. mimeo.

(1969) “Redefinición de la dependencia y proceso de marginalización en América Latina” en CEPAL - División de Asuntos Sociales. Santiago de Chile.

(1970) "Carácter y perspectiva del actual régimen militar en el Perú". Centro de Estudios SocioEconómicos, Universidad de Chile. Santiago de Chile. Documento de Seminario.

(1970) "Polo marginal y mano de obra marginal en América Latina" en Quijano, A. Imperialismo y marginalidad en América Latina. Lima: Mosca Azul Ediciones, 1977. pp. 239-287

(1971) Nacionalismo, Neoimperialismo y Militarismo en el Perú. Buenos Aires: Periferia.

(1971) "Dominación y Cultura" en Revista Latinoamericana de Ciencias Sociales. N. 1-2. Santiago de Chile.

(1972) (ed.) Sociedad y Política. Revista de Análisis y Debate Político. Años: de 1972 a 1983. Lima.

(1972) "Imperialismo y Capitalismo de Estado" en Sociedad y Política. N. . 1, junio. Lima.

(1972) "La "vía chilena" dos años después" en Sociedad y Política. N. 2, octubre. Lima.

(1972) "Alternativas de las ciencias sociales en América Latina" en Desarrollo Indoamericano. Vol. 21, N. ${ }^{\circ}$, octubre. Barranquilla.

(1973) "La coyuntura política y las tareas de la clase obrera" en Sociedad y Política. N. 4, septiembre. Lima.

(1973) “Integración y Dependencia” en Economía. N. 57, enero, Tercera Época. Quito

(1973) "Crisis de hegemonía política en América Latina" en Economía. N. 58, junio, Tercera Época. Quito.

(1973) “El marco estructural condicionante de los problemas de participación social en América Latina" en Murga y Boils (eds.). América Latina, Dependencia y Subdesarrollo. San José: EDUCA.

(1973) “Política y Desarrollo en América Latina” en Murga y Boils (eds.). América Latina, Dependencia y Subdesarrollo. San José: EDUCA.

(1973) "Die agrarreform in Peru" en Feder, Ernst (ed.) Gewalt und Ausbeutung. Lateinamerikas Landwirtschaft. Hamburg: Hoffman und Campe Verlag. Traducción al castellano: “La reforma agraria en el Perú" en Problema agrario y movimientos campesinos. Lima: Mosca Azul Editores, 1979. 
(1973) El Imperialismo en el Perú. Arequipa: Universidad de San Agustín.

(1973) [en coautoría con] Weffort, Francisco. Populismo y Marginalidad en América Latina. San José: EDUCA.

(1973) "Introducción" en Pimentel, Carmen (ed.). Vidas Marginales. Santiago de Chile: Ed. Universitaria.

(1974) Crisis imperialista y clase obrera en América Latina. Edición del autor. Lima.

(1974) "Sobre la naturaleza actual de la crisis del capitalismo" en Crisis imperialista y clase obrera en América Latina. Edición del autor. Lima.

(1974) “El nuevo terreno de la lucha de clases y los problemas de la revolución en América Latina" en Crisis imperialista y clase obrera en América Latina. Edición del autor. Lima.

(1974) "Perou, de la conciliation a l'affrontement" en Politique Aujourd'hui N. 1-2: 87-100, febrero. París. Traducción al castellano: “De la Conciliación al Enfrentamiento" en Latin American Perspectives, Vol. II, N. ${ }^{\circ}$ 1, Issue 4, primavera de 1975.

(1974) “Imperialismo y Relaciones Internacionales en América Latina” en Cotler, J. y Fagen, R. (comps.) Relaciones Politicas entre América Latina y Estados Unidos. Buenos Aires: Amorrortu.

(1974) “Capitalismo y Corporativismo” en Economía. N. 60. Quito.

(1975) “La 'segunda fase' de la 'revolución peruana' y la lucha de clases” en Sociedad y Política. N. 5, noviembre. Quito.

(1976) “¿Frente popular antiimperialista o frente de trabajadores?” en Sociedad y Política. N. ${ }^{\circ}$ 6, marzo. Lima.

(1976) “La doble táctica de la actual ofensiva imperialista en América Latina” en Economía. N. 67, noviembre. Quito.

(1977) Dependencia, Cambio Social y Urbanización en América Latina. Lima: Mosca Azul.

(1977) Imperialismo y Marginalidad en América Latina. Lima: Mosca Azul.

(1977) "Las nuevas condiciones de la lucha de clases en el Perú" en Sociedad y Política. N. 7 , mayo. Lima.

(1977) “El Perú en la crisis de los años 30” en González Casanova, Pablo (coord.) América Latina en los años treinta. Instituto de Investigaciones Sociales - UNAM.

(1978) Imperialismo, Clases Sociales y Estado en el Perú 1895-1930. Lima: Mosca Azul.

(1978) "Comentario a la ponencia de Orlando Fals Borda" en Simposio Mundial de Cartagena, Crítica y politica en ciencias sociales. Vol. I. Bogotá: Punta de Lanza / Universidad de Los Andes.

(1978) “Un agrio tupo fascista" en Sociedad y Política Quincenal. N. ${ }^{\circ}$ 1, primera quincena de febrero. Lima.

(1978) "Imperialismo y campesinado: sus actuales condiciones en el Perú" en Churmichasun (Huancayo) N. 6-7, octubre.

(1978) "No una sino muchas Malvinas" en Sociedad y Política Quincenal. Lima N. 2.

(1979) Problemas Agrarios y Movimientos Campesinos. Lima: Mosca Azul.

(1979) "Prólogo: José Carlos Mariátegui: reencuentro y debate" en Mariátegui, José Carlos. 7 ensayos de interpretación de la realidad peruana. Caracas: Biblioteca Ayacucho.

(1979) [anónimo] “Qué es y qué no es el socialismo?" (Parte I) en Revolución socialista. Movimiento Revolucionario Socialista. N. ${ }^{\circ} 28$, setiembre. Lima.

(1979) [anónimo] “Qué es y qué no es el socialismo?” (Parte II) en Revolución socialista. Movimiento Revolucionario Socialista) N. 29 , octubre. Lima.

(1980) Dominación y cultura. Lo cholo y el conflicto cultural en el Perú. Lima: Mosca Azul. 
(1980) "Las condiciones del enfrentamiento" en Sociedad y Política. N. 8: 6-16, febrero. Lima (1980) [anónimo] "ARI: ¿Por qué y cómo se desintegró? ¿Quiénes son los responsables?". Documento del Movimiento Revolucionario Socialista. Lima: Sociedad y Política Ediciones.

(1980) "Los usos de la democracia burguesa" en Sociedad y Política. N. ${ }^{\circ}$ 10, noviembre. Lima.

(1980) [seudónimo] Oruro, José “Bolivia: la tragedia de las equivocaciones" en Sociedad y Política. N. ${ }^{\circ}$ 10, noviembre. Lima.

(1981) “La política de la guerra y la guerra de la política” en Sociedad y Política. N. 11 , marzo. Lima. (1981) "Poder y democracia en el socialismo" en Sociedad y Política. N. 12, agosto. Lima.

(1981) "Sociedad y Sociología en América Latina" en Revista de Ciencias Sociales. Río Piedras: Centro de Investigaciones Sociales, Universidad de Puerto Rico. Vol. XXIII, N. ${ }^{\circ}$ 1-2, marzo-junio.

(1981) [en coautoría con] Lauer, Mirko “Introducción” en Bahro, Rudolf. El socialismo realmente existente: seis conferencias críticas. Lima: Mosca Azul Editores.

(1982) "Notas sobre tecnología del transporte y desarrollo urbano" en AA.VV. Aproximación Crítica a la Tecnología en el Perú. Lima: Mosca Azul.

(1982) "Sociedad, poder y sociología en el Perú" en I Congreso Peruano de Sociología, Huacho.

(1983) "Revolución democrático-burguesa y revolución antioligárquico-nacionalista: el proceso del Estado en el Perú" en Homines. Universidad Interamericana de Puerto Rico. Vol. VII, N. 1 y 2, febrero-diciembre.

(1984) "Arguedas: la sonora banda de la sociedad" en Hueso Húmero. N. 19, octubre-diciembre. Lima.

(1984) Las ideas y los intereses frente al Pacto Andino. Lima: Junta del Acuerdo de Cartagena.

(1984) “Transnacionalización y crisis de la economía de América Latina" en Cuadernos del Cerep. San Juan.

(1985) "La migración humana" en Hueso Húmero. N. 20, enero-marzo. Lima.

(1986) “Las ideas son cárceles de larga duración” en David y Goliath. Año XVI, N. 49, julio. Buenos Aires: CLACSO.

(1986) "La tensión del pensamiento latinoamericano" en La Torre, Revista General de la Universidad de Puerto Rico. Año XXXIV, N. 131, 132, 133, enero-septiembre. Coloquio Marx ¿Para qué? Sociedad Puertorriqueña de Filosofía. Versión en esta antología: Hueso Húmero. N. 22: 106-125, julio. Lima.

(1987) "América Latina: los compromisos del conflicto" en Silva M., José Agustín (ed.) Paz, Seguridad y Desarrollo en América Latina. Caracas: Nueva Sociedad.

(1988) Modernidad, Identidad y Utopía en América Latina. Lima: Sociedad y Política Ediciones.

(1988) "Lo público y lo privado: un enfoque latinoamericano" en Modernidad, Identidad y Utopía en América Latina. Lima: Sociedad y Política Ediciones.

(1988) “Notas sobre Informalidad y Poder en América Latina" en Documento del Seminario Empleo e Informalidad. Mayo. Quito.

(1989) "Paradoxes of Modernity in Latin America". International Journal of Politics, Culture, and Society, Vol. 3, N. ${ }^{\circ}$, winter, pp. 147-177.

(1989) “La nueva heterogeneidad estructural de América Latina” en Sonntag, Heinz R. (comp.) ¿Nuevos Temas, Nuevos Contenidos? Caracas: UNESCO / Nueva Sociedad.

(1990), “La Razón del Estado", Urbano, H. y Lauer, M. (eds.). Modernidad en los Andes. Cusco: Centro de Estudios Regionales Andinos "Bartolomé de las Casas".

(1990) “La crisis en Europa del Este y la Izquierda en América Latina" en Página Libre. Suplemento Cultura Libre, 29 de agosto. Versión en esta antología: El Fujimorismo y el Perú. Lima: SEDES, 1995. 
(1990) “Notas sobre los problemas de la investigación social en América Latina” en Revista de Sociología. Facultad de Ciencias Sociales, Universidad Nacional Mayor de San Marcos. Vol. 6, N. ${ }^{\circ}$ 7. Lima.

(1990) “Estética de la Utopía” en Hueso Húmero. N. 27, diciembre. Lima.

(1991) (ed.) Textos Básicos de José Carlos Mariátegui. México / Lima: Fondo de Cultura Económica. Selección, Introducción y Prólogos a cada Sección de Aníbal Quijano.

(1991) “La Modernidad, el Capital y América Latina nacen en el mismo día” en Revista del Centro de Educación y Cultura ILLA N. ${ }^{\circ}$ 10, enero. Lima.

(1991) “Poder y Crisis en América Latina” en Paginas. N. 109, junio. Lima.

(1991) “Trotsky (entre paréntesis)” en Revista Sí. N.` 64, julio. Lima.

(1992) “Colonialidad y Modernidad / Racionalidad" en Perú Indígena. Vol. 13, N. 29: 11-20. Lima.

(1992) [en coautoría con] Wallerstein, Immanuel "Americanity as a concept. Or The Americas in the Modern World-System" en International Journal of Social Science. París: UNESCO) N. 134 , noviembre. Discutido en el Simposio Mundial por el 500 Aniversario de América, organizado por UNESCO en París, en octubre de 1992.

(1992) [en coautoría con] Wallerstein, Immanuel "La americanidad como concepto, o América en el moderno sistema mundial" en Revista Internacional de Ciencia Sociales (Organización de las Naciones Unidas para la Educación, la Ciencia y la Cultura) Vol. XLIV, N. ${ }^{\circ}$, diciembre.

(1992) "Notas sobre a questão da identidade e nação no Peru" en Estudos Avançados. Vol. 6, N. 16. San Pablo: Universidade de São Paulo. En castellano: en Márgenes. Año V, N. 9. Lima.

(1992) "Profesión y Oficio de la Sociología" en Universidad y Sociedad. Año 2, N. ㄴ 24-25. Lima.

(1992) “Que América Latina é esta?" en Brasil Agora. N. 36.

(1992) “Os embriões de uma nova história" en Jornal da USP. Año VI, N. 239. São Paulo: Universidade de São Paulo.

(1993) “'Raza', 'Etnia' y 'Nación' en Mariátegui: Cuestiones Abiertas”, Forgues, R. (ed.). José Carlos Mariátegui y Europa: La Otra Cara del Descubrimiento. Lima: Editora Amauta.

(1993) “A América Latina, Sobreviverá?" en São Paulo em Perspectiva. Vol. 7, N. 2: 60-67. San Pablo: SEADE.

(1993) “América Latina en la Economía Mundial" en Problemas del Desarrollo. Vol. XXIV, N. 95, octubre-diciembre. México: Instituto de Investigaciones Económicas - UNAM.

(1993) "Réflexions sur l'Interdisciplinarité, le Développement et les Relations Interculturelles" en Entre Savoirs. L'interdisciplinarité en acte: enjeux, obstacles, résultats. París: UNESCO / ERES.

(1994) “La sonrisa y su gato en el País de las Maravillas. ¿Qué celebramos en el centenario de José Carlos Mariátegui?" en QUEHACER. N. 89: 47-52, mayo-junio. Lima: DESCO.

(1994) "Prólogo: El Sueño Dogmático" en Fernández, Oswaldo. Mariátegui o la Experiencia del Otro. Lima: Amauta.

(1994) “Colonialité du Pouvoir et Démocratie en Amérique Latine” en Future Antérieur: Amérique Latine, Démocratie Et Exclusion. París: L’Harmattan. En castellano: “Colonialidad del poder y democracia en América Latina" en Revista Debate. Vol. XVI, N. 77 , marzomayo. Lima.

(1994) “El Precio de la Racionalidad” en Gaceta Sanmarquina. Año 5, N. 22: 4. Lima: UNMSM.

(1994) "Líneas de investigación prioritarias para América Latina" en Los problemas actuales de las ciencias sociales en el Ecuador y América Latina. Memorias del VII Encuentro de 
historia y realidad económica y social del Ecuador y América Latina. Cuenca: Instituto de Investigaciones Sociales. pp. 95-104.

(1995) “El Marxismo en Mariátegui: Una Propuesta de Racionalidad Alternativa” en Sobrevilla, David (ed.) El marxismo de José Carlos Mariátegui. Seminario efectuado el 2 de agosto de 1994. Lima: Amauta.

(1995) “El Fujimorismo y el Perú" en La República. Lima. 13 de marzo.

(1995) “¿Dónde comienza la resistencia?” en La República. Lima. 22 de junio.

(1995) “Las manos sobre la universidad" en La República. Lima. 30 de junio.

(1995) “Educación y Democracia: la misma batalla” en La República. Lima. $1^{\circ}$ de julio

(1996) “Un tiempo nuevo" en La República. Lima $1^{\circ}$ de mayo.

(1996) “¿La razón de cuál Estado?” en La República. Lima. 30 de diciembre.

(1996) "Florestán Fernándes: una biografía completa" en Estudos Avançados. Vol. 10, N. ⒉ 26. San Pablo: USP - Instituto de Estudos Avançados.

(1996) “La historia recién comienza” La República. Lima. 8 de diciembre.

(1996) "Presentación" en Coronado, Jaime y Pajuelo, Ramón, Villa El Salvador: poder y comunidad. Lima: CECOSAM / CEIS.

(1996) “Las navidades de Fujimori” en Jornal Do Brasil. Río de Janeiro.18 de diciembre.

(1997) “El fin de cuál Historia?” en Análisis Político. N. 32 , septiembre-diciembre. Instituto de Estudios Políticos y Relaciones Internacionales, UNC.

(1997) “El silencio y la escritura” en QUEHACER. N. 107, julio. Lima: DESCO.

(1997) “Estado-nación, Ciudadanía y Democracia: cuestiones abiertas" en Gonzáles, Helena y Schmidt, Heidulf (orgs.) Democracia para una Nueva Sociedad. Caracas: Nueva Sociedad. (1997) “Viva la vida, Eleodoro!” en La casa de cartón de Oxy: Revista de cultura. N. 13. Lima.

(1997) “Si no cambia no será estable" en IDEELE. N. 100, agosto. Lima.

(1997) “El tiempo nuevo ha comenzado" en La República. Lima $1^{\circ}$ de mayo.

(1997) "Raúl Porras, el otro magisterio" en La República. Lima 12 de mayo.

(1997) “Globalización y exclusión desde el futuro" en La República. Lima 24 de agosto.

(1997) "Populismo y Fujimorismo", en Villena, Sergio (editor), Neopopulismo y democracia. Estudios andinos, Cuadernos de Ciencias Sociales N. ${ }^{\circ}$ 96. San José: FLACSO Programa Costa Rica.

(1997) "Voto en contra" [segundo postscriptum de "Populismo y Fujimorismo"] en Burbano de Lara, F. (comp.) El Fantasma del Populismo. Caracas: Nueva Sociedad / ILDIS, 1998.

(1998) La Economía Popular y sus caminos en América Latina. Lima: Mosca Azul Editores / CEIS / CECOSAM.

(1998) “¿Del 'polo marginal' a la 'economía alternativa'?” en La Economía Popular y sus caminos en América Latina. Lima: Mosca Azul Editores / CEIS / CECOSAM.

(1998) “¿Qué tal Raza!” en Pimentel, Carmen (ed.). Familia y Cambio Social. Lima: CECOSAM.

(1998) "Colonialidad, Poder, Cultura y Conocimiento en América Latina" en Anuario Mariateguiano. Vol. IX, N. 9. Lima.

(1998) "La Política de la Escritura" en Hueso Húmero. N. ${ }^{\circ} 33$. Lima.

(1998) “Un Fantasma Recorre el Mundo” en Hueso Húmero. N. ${ }^{\circ} 134$. Lima.

(1998) “Más Temprano que Tarde" en La República. Lima. 14 de diciembre.

(1998) “Un Viajero Francés al Final del Siglo XX" en Encuentros. Instituto del Bien Común. Agosto de 1999, Lima.

(1998) “Work in a Turning Point?" en ISA Bulletin. N. 75-76, primavera. Madrid: Universidad Complutense. 
(1999) “El Discurso de lo Social: Notas para el Debate” en Henríquez, Narda (ed.) Construyendo Una Agenda Social. Lima: PUCP.

(1999) "Prólogo" en Ortiz, Carolina. La letra y los cuerpos subyugados: heterogeneidad, colonialidad y subalternidad en cuatro novelas latinoamericanas. Quito: UASB Sede Ecuador / CEN.

(1999) "Fiesta y Poder en el Caribe (Notas a propósito de: Quintero, Ángel. Salsa, Sabor y Control. México: Siglo XXI, 1998)" en Diálogo. San Juan. Abril.

(1999) "Coloniality of Power and its Institutions" en Documento del seminario Internacional sobre Colonialidad del poder y sus ámbitos. Binghamton University, abril.

(1999) “Colonialidad del Poder, Cultura y Conocimiento en América Latina”, Dispositio. Crítica Cultural en Latinoamérica: Paradigmas globales y enunciaciones locales, Vol. 24, N. 51, pp. 137-148

(2000) “¿La Impunidad como Programa?” en ALAI. N. 311, abril. Quito.

(2000) “A reorganizar el Perú" en Liberación. 7 de septiembre. Lima.

(2000) [entrevista] "América Latina tiende hacia lo comunal" en Aguirre, Milagros (org.) Controversia: Ecuador hoy: cien miradas. Quito: FLACSO / El Comercio / Ediecuatorial.

(2000) "Colonialidad del poder y clasificación social" en Arrighi, Giovanni y Goldfrank, Walter L. (eds.) Festschrift For Immanuel Wallerstein en Journal of World Systems Research. Vol. VI, N. ${ }^{\circ}$ 2: 342-388, otoño-invierno, Colorado. Edición Especial.

(2000) “Colonialidad del poder, eurocentrismo y América Latina" en Edgardo Lander (comp.) La colonialidad del saber: eurocentrismo y ciencias sociales. Perspectivas Latinoamericanas. Buenos Aires: CLACSO.

(2000) “El Fantasma del Desarrollo en América Latina" en Revista Venezolana de Economía y Ciencias Sociales. N. ${ }^{\circ}$ 2. Caracas: UCV.

(2000) "El fraude electoral más grande de la historia" en La República. Lima. 26 de marzo.

(2000) "El Fujimorismo, la OEA y el Perú" en ALAI. N. 317, 25 de julio. Quito.

(2000) "La alternativa: Gobierno Provisional de las Municipalidades" en Nueva sociedad. N. 168, julio-agosto. Caracas.

(2000) "Las últimas elecciones del fujimorismo" en Anuario Social y Político de América Latina y el Caribe. N. ${ }^{\circ}$ 4: 26-38. Caracas: FLACSO / UNESCO / Nueva Sociedad.

(2000) Carta a la Coordinadora de Derechos Humanos. Binghamton, Nueva York. 21 de septiembre. (2001) “¿Y después del 11 de septiembre, Nueva York?” en Ecuador Debate. N. 54, diciembre. Quito.

(2001) "Colonialidad del Poder, Globalización y Democracia" en Tendencias Básicas de Nuestra Época. Caracas: Instituto de Altos Estudios Internacionales Pedro Gual. pp. 21-65.

(2001) "El Regreso del Futuro y las Cuestiones del Conocimiento" en Hueso Húmero. N. 38. Lima.

(2001) "Poder y Derechos Humanos" en Pimentel, Carmen (comp.) Poder, Salud Mental y Derechos Humanos. Lima: CECOSAM.

(2001) "Entre la Guerra Santa y la Cruzada" en ALAI. N. 341, octubre. Quito.

(2002) "Sistemas alternativos de produção" en De Sousa Santos, Boaventura (org.) Produzir para viver. Os caminhos da produção não capitalista. Río de Janeiro: Civilização Brasileira.

(2002) "El Fujimorismo del gobierno Toledo" en OSAL. Observatorio Social de América Latina. N. 7, junio. Buenos Aires: CLACSO.

(2002) "El nuevo imaginario anticapitalista" en ALAI. N. 351, marzo. Quito.

(2002) "Venezuela: ¿un nuevo comienzo?" en ALAI. $1^{\circ}$ de mayo. Quito.

(2003) “Notas sobre raza y democracia en los países andinos" en Revista Venezolana de Economía y Ciencias Sociales (Caracas: UCV) Vol. 9, N. 1: 53-59, enero-abril 
(2003) "Allende otra vez: en el umbral de un nuevo periodo histórico" en Il Manifesto (Roma). N. ${ }^{\circ} 11$. Versión en esta antología: en ALAI. 13 de septiembre de 2000. Quito.

(2003) "Tanta memoria permanece" en Libros \& Artes. Revista de Cultura de la Biblioteca Nacional del Perú. N. ${ }^{\circ}$ 6: 1617, diciembre.

(2003) "El Trabajo en el Umbral del Siglo XXI" en Founou-Tchuigoua, Bernard; Sy, Sams Dine y Dieng, Amady A. (eds) Pensée sociale critique pour le XXie siècle / critical social thought forthe XXIst century. Mélanges en I'honneur del Essais in honour of Sami Amin. París: L'Harmattan. pp. 131-149

(2004) “El laberinto de América Latina: ¿Hay otras salidas?” en Revista Venezolana de Economía y Ciencias Sociales. 10, N. ${ }^{\circ}$, enero-abril. Caracas: UCV.

(2004) “Immanuel Wallerstein: instancias y trazos" en Socialismo y participación. N. 98. Lima.

(2004) “O 'movimento indígena' e as questões pendentes na América Latina" en Política Externa. Vol. 12, N. ${ }^{\circ}$ 4: 77-95, marzo-abril-mayo. San Pablo: Instituto de Estudios Internacionales -USP.

(2005) “Los molinos de viento de América Latina" en Libros y Arte, N. ${ }^{\circ} 10$. Re publicado como "Don Quijote y los molinos de viento en América Latina" en Revista Pasos N. ${ }^{\circ}$ 127, septiembre-octubre, 2006. San José, Departamento Ecuménico de Investigaciones.

(2005) "El "movimiento indígena" y las cuestiones pendientes en América Latina" en Revista Tareas. N. ${ }^{\circ}$ 119: 31-62, enero-abril. Panamá: CELA / Justo Arosemena.

(2006) “Estado-nación y 'movimientos indígenas' en la región andina: cuestiones abiertas" en OSAL. Vol. 7, N. ${ }^{\circ}$ 19, enero-abril. Buenos Aires: CLACSO.

(2006) “El Fracaso del Moderno Estado-nación” en León, Irene. La Otra América en Debate. Quito: I Foro Social Américas.

(2007) “Treinta años después: otro reencuentro. Notas para otro debate” en Mariátegui, José Carlos. 7 Ensayos de interpretación de la realidad peruana. Tercera edición. Caracas: Biblioteca Ayacucho.

(2007) "De la resistencia a la alternativa" en ALAI. 30 de octubre. Quito.

(2007), "El color de la cárcel en América Latina. Apuntes sobre la colonialidad de la justicia en un continente en desconstrucción" Nueva Sociedad. N. ${ }^{\circ}$ 208, marzo-abril.

(2007), "Raza es signo" en Segato, R. La Nación y sus Otros. Buenos Aires, Prometeo.

(2007) "Interculturalidad y colonialidad del poder. Un pensamiento y posicionamiento "otro" desde la diferencia colonial", Castro-Gómez, S. et R. Grosfoguel (eds.): El giro decolonial. Reflexiones para una diversidad epistémica más allá del capitalismo global. Bogotá, Siglo del Hombre Editores.

(2008) “Colonialidad del Poder, Sexo y Sexualidad", Pimentel Sevilla, C. (org.). Poder, Ciudadanía, Derechos Humanos y Salud Mental en el Perú. Lima, CECOSAM.

(2008) “Treinta Años Después: Otro Reencuentro. -Notas para Otro Debate", Simposio Internacional Conmemorativo de la aparición de la obra clásica José Carlos Mariátegui. Año I, N. 2, Lima, marzo.

(2008) “El movimiento indígena y las cuestiones pendientes en América Latina”. El Cotidiano. N. 151, Universidad Autónoma Metropolitana, Distrito Federal, México, septiembreoctubre, pp. 107-120. Disponible en:http://www.redalyc.org/src/inicio/ArtPdfRed. jsp?iCve $=32511865013$

(2008) "Solidaridad" y capitalismo colonial/moderno" en Otra Economía. Vol. 2, N. 2, Primer semestre. Buenos Aires. 
(2008) “Des/colonialidad del poder: el horizonte alternativo" en ALAI. 17 de mayo. 176. Quito, (2008) [en coautoría con] Ceceña, Ana María Esther "Emergencia en Haití" en ALAI.10 de abril. Quito.

(2009) "Colonialidad del Poder y Des/colonialidad del Poder". Conferencia dictada en el XXVII Congreso de la Asociación Latinoamericana de Sociología, Buenos Aires.

(2009) "Colonialidad del Poder, Sexo y Sexualidad" en Pimentel Sevilla, Carmen (org.) Poder, ciudadanía, derechos humanos y salud mental en el Perú. Lima: Centro Comunitario de Salud Mental, CECOSAM.

(2009) "La crisis del horizonte de sentido colonial / moderno / eurocentrado" en Mejía Navarrete, Julio (ed.) Sociedad, cultura y cambio en América Latina. Lima: Universidad Ricardo Palma.

(2009) “Las paradojas de la colonial / modernidad / eurocentrada" en Hueso Húmero. N. 53. Lima.

(2009) “Otro horizonte de sentido histórico" en ALAI. Año XXXIII Segunda Época, N. ${ }^{\circ} 441,29$ de febrero. Quito.

(2009) Interculturalidad, estado, sociedad: luchas (de)coloniales de nuestra época. Quito: Universidad Andina Simón Bolívar.

(2010) “Los cauces profundos de la raza latinoamericana: una relectura del mestizaje”. Crítica y Emancipación. Año II, N. ${ }^{\circ}$ 3, Primer Semestre.

(2010) “'Bien Vivir' para Redistribuir el poder. Los pueblos indígenas y su propuesta alternativa en tiempos de dominación global" en Pobreza, desigualdad y desarrollo en el Perú. Informe 2009-2010 Oxfam. Julio.

(2011) "Género y colonialidad: en busca de claves de lectura y de un vocabulario estratégico descolonial". Bidaseca, K., et V. Vazquez Laba (Comp.): “Feminisimos y Poscolonialidad. Descolonizando el feminismo desde y en América latina". Buenos Aires: Ediciones Godot.

(2011) “¿Bien Vivir?: entre el 'desarrollo' y la des/colonialidad del poder” en Ecuador Debate. N. 84, diciembre. Quito.

(2011) “El nudo arguediano" en Centenario de José María Arguedas: sociedad, nación y literatura. Lima: Universidad Ricardo Palma - Editorial Universitaria.

(2012) "Brechas descoloniales para una universidad nuestroamericana", Revista Casa de las Américas, N. 266 , enero-marzo.

(2012) "O BemViver e as formas de felicidade", Brasil de Fato, http:// www.brasildefato.com.br/ node/8584, 10/01/2012 Walsh, C.,

(2012) “Ser el cuarto Mariátegui" en Mariátegui Chiappe. Javier José Carlos Mariátegui: Formación, contexto e influencia de un pensamiento. Lima: URP.

(2012) “El moderno Estado-nación en América Latina: cuestiones pendientes” en Mejía Navarrete, Julio. América Latina en debate. Sociedad, conocimiento e intelectualidad. Lima: URP.

\section{Entrevistas y debates}

(1972) Cordera, Rolando y Hernández, Salvador "Perú a cuatro años de un proyecto de reforma" en Siempre. N. ${ }^{\circ}$ 1.011, 8 de noviembre. México.

(1981) Hildebrandt, César "Entrevista" en Cambio de Palabras. Lima: Mosca Azul Editores.

(1985) Rochabrún, Guillermo (ed.) y Arguedas, José María et al. La Mesa Redonda sobre "Todas las Sangres" del 23 de junio de 1965. Lima: PUCP / IEP. 
(1990) Pease, Franklin; Manrique, Nelson y Adrianzén, Alberto “La presencia polémica de Alberto Flores Galindo" en Pretextos, Vol. 1, N. ${ }^{\circ}$ 1: 45-60, agosto.

(1992) Bonilla, Heraclio (ed.) Después de la caída. El significado de la crisis del socialismo para América Latina y Europa del Este. Quito: FLACSO.

(1993) “El Tiempo de la Agonía” en Perú entre el Desafío de la Violencia y el Sueño de lo Posible. Forgues, Roland (ed.) Lima: Minerva. pp. 287-309.

(1993) Moraes, Carlos y Porto, Regina "Aníbal Quijano. Entrevista" en Nuestra América. N. 1. San Pablo.

(1993) Burga, Manuel; Franco, Carlos; Gutiérrez, Gustavo; Hernández, Max y López Soria, José Ignacio. “¿Por qué seguir discutiendo 1492?” en Hueso Húmero. N. 29: 3-67. Lima.

(1994) [en coautoría con] Gutiérrez, Gustavo "Mariátegui contra la Expropiación de la Utopía” en Cuestión de Estado. Año 2, N. 8-9: 37-51. Lima.

(1994) "El riesgo es el fundamentalismo. Aníbal Quijano y la crisis de paradigmas" en La República. Lima. 27 de marzo.

(1995) Adrianzén, Alberto y Burgos, Hernando “Entrevista exclusiva con Aníbal Quijano” en QUEHACER. N. ${ }^{\circ}$ 94, marzo-abril. Lima: DESCO.

(1995) Lévano, César "La hora cero" en Revista Sí. Año 8, N. 423, 24 de abril.

(2000) Degregori, Carlos Iván y Reyna, Carlos “El intelectual frente al pensamiento único. Una entrevista con Aníbal Quijano" en QUEHACER. N. ${ }^{\circ}$ 125, julio-agosto. Lima: DESCO.

(2000) Navarro, Luis “Entrevista. No sólo se trata de deshacernos de Fujimori, es hora de reorganizar la sociedad peruana" en Liberación. Lima. Octubre.

(2002) “Desconsolidación de la democracia. Discontinuidades y un nuevo sentido. Diálogo con Aníbal Quijano" en Ecuador Debate. N. ${ }^{\circ}$ 57, diciembre. Quito.

(2003) De la Cadena, Marisol “Escribir otra historia del Perú. Debate: Hugo Guerra; Abelardo Oquendo; Pepi Patrón; Aníbal Quijano; Cecilia Rivera; Carlos Tovar Samanez; José Ugaz" en Cuestión de Estado, N. 32 , noviembre.

(2004) Navarro, María. "El neoliberalismo arrastra a América Latina a la esclavitud" en La Onda Digital, junio.

(2006) Pereira Filho, Jorge "Romper el eurocentrismo" en ALAI. América Latina en Movimiento, 28 de junio.

(2006) Pando Moreno, Adán y Arévalo Guízar, Gabriela "América Latina: globalización y nacionalismo. Diálogo con Aníbal Quijano" en Revista Interamericana de Educación de Adultos, Año 28, N. 2 julio-diciembre, nueva época.

(2007) León, Osvaldo “Entrevista a Aníbal Quijano: en Perú hay un pueblo movilizado" en ALAI. N. ${ }^{\circ}$ 424-425, 22 de octubre. Quito.

(2008) Hueso Humero. "Reabrir cuestiones que parecían resueltas. Una conversación con Aníbal Quijano" en Hueso Húmero. Lima N. 51.

(2009) Ríos, Jaime “Diálogo sobre la crisis y las ciencias sociales en América Latina” en Revista del Colegio de Sociólogos del Perú. Año I, N.` 1, agosto. Lima.

(2011) Mujica Pinilla, Ramón (ed.) Arguedas: Poética de la Verdad. Segunda mesa redonda sobre "Todas las Sangres". Lima: Biblioteca Nacional del Perú.

(2011) Aceves Velázquez, Wendy “El neoliberalismo está en plena deslegitimación y hay una reacción mundial" en La Gaceta. Guadalajara. 27 de junio. 


\section{Antologías}

Assis Climaco, D. (comp.). (2014). Quijano, Aníbal. Cuestiones y horizontes: de la dependencia histórico-estructural a la colonialidad/descolonialidad del poder. Buenos Aires: CLACSO.

Palermo, Z., Quintero, P. (comp.). (2014). Aníbal Quijano: textos de fundación. Buenos Aires: Ediciones del Signo.

Sergio Villena Fiengo. Boliviano-costarricense, Doctor en Estudios de la Sociedad y la Cultura por la Universidad de Costa Rica. Profesor catedrático en la Escuela de Sociología de la UCR, donde imparte regularmente la asignatura "Sociología latinoamericana" y "Sociología de la cultura". Es también subdirector en el Instituto de Investigaciones Sociales, en la misma universidad. Entre sus publicaciones recientes se encuentra el libro El perro está más vivo que nunca. Arte, infamia y contracultura en la aldea global (Germinal, 2015, segunda edición), así como los artículos “Intervenciones intempestivas en Centroamérica. El anti-ceremonial público en la obra de Regina José Galindo" (Revista de Estudios Globales y Arte Contemporáneo, Barcelona, 2015) y ¿Adiós a la globananalización? "La Décima" bienal centroamericana y el campo artístico regional (Hoja filosófica, Herdia, 2016). Mayor información en: https://ucr.academia.edu/ SergioVillenaFiengo.

Contacto: sergio.villena@ucr.ac.cr 
